\title{
Spatial and Temporal Variability of Total Column Ozone over the Indian Subcontinent: A Study Based on Nimbus-7 TOMS Satellite
}

\author{
Vazhathottathil Madhu \\ Department of Atmospheric Sciences, Cochin University of Science and Technology, Cochin, India \\ Email: $\underline{\text { madhuv68@gmail.com }}$
}

Received 10 October 2014; revised 12 November 2014; accepted 24 November 2014

Copyright (C) 2014 by author and Scientific Research Publishing Inc.

This work is licensed under the Creative Commons Attribution International License (CC BY).

http://creativecommons.org/licenses/by/4.0/

(c) (i) Open Access

\begin{abstract}
The distribution and variability of ozone is very important to the atmospheric thermal structures, and it can exert their greater influence on climate. Present study is based on Nimbus-7 TOMS overpass column ozone for a period of 14 years (1979-1992) over twelve selected Indian stations from south to north latitude and it explores the spatial and temporal variability of Total Column Ozone (TCO). For this investigation an advanced statistical methods such as Factor Analysis and Morlet wavelet transform are employed. Total column ozone variability over these stations is grouped into two clusters (Eigen value greater than 1) by the Multivariate Factor analysis. It is found that the Group I stations shows the same nature of variability mainly due the first factor as the primarily loading and whereas as the Group II stations shows the same nature of variability due to second factor as the primary loading. The correlation value of TCO decreases from 0.9 to 0.32 as we move from south to north stations (lower latitude to higher latitude). The total column ozone over tropical stations is maximum during monsoon season with peak in the month of June and that for the higher latitude stations is during the pre-monsoon season. Annual average of TCO for tropical stations is about $265 \mathrm{DU}$ and that for subtropical stations is about $280 \mathrm{DU}$ and a difference of $15 \mathrm{DU}$ is noted in the annual average of TCO between tropical and subtropical stations. A large reduction in TCO is noted over the Indian subcontinent in the year 1985, the same year in which the ozone hole over Antarctica was discovered. It is also found that two prominent oscillations are present in total column ozone one with a periodicity of 16 to18 months and other with 28 to 32 months (QBO periodicity) apart from the annual oscillations. These oscillations are found to be significant at above $95 \%$ level of confidence when tested with Power Spectrum method. Tropical TCO shows high concentration during the westerly phase and low concentration during the easterly phase of the equatorial stratospheric quasi-biennial oscillation.
\end{abstract}

\section{Keywords}

Total Column Ozone, Quasi-Biennial Oscillation, Interannual Variability, Morlet Wavelet 


\section{Introduction}

Atmospheric ozone plays an important role in the global weather and climate even though it makes up less than one-millionth of the volume of the atmosphere. Most of the ozone concentration is found in the stratosphere (about 90\%), a region that begins about 10 - 16 kilometers above Earth's surface and extends up to about 50 kilometers altitude. Maximum ozone concentration found in the lower stratosphere is commonly known as the "ozone layer". The remaining ozone concentration about $10 \%$ is found in the troposphere. Ozone in the stratosphere (good ozone) has various environmental consequences for humans and other life forms than excess ozone in the troposphere (bad ozone). In the cold upper troposphere, ozone has a potent greenhouse effect [1] [2] Stratospheric ozone is naturally formed in chemical reactions involving ultraviolet sunlight and oxygen molecules. Sunlight (UV radiations) breaks one oxygen molecule $\left(\mathrm{O}_{2}\right)$ to two oxygen atoms $(2 \mathrm{O})$ which then combine with an oxygen molecule to produce an ozone molecule $\left(\mathrm{O}_{3}\right)$. These reactions occur continuously wherever ultraviolet sunlight is present in the stratosphere; hence the greatest ozone production occurs in the tropical stratosphere.

On the earth's surface, ozone is produced via chemical reactions involving naturally occurring gases and gases from pollution sources. Fossil fuel combustion is a primary pollution source for tropospheric ozone production. Production reactions primarily involve hydrocarbon and nitrogen oxide gases and require sunlight. Ozone and the hydroxyl radical $(\mathrm{OH})$ plays important roles in the oxidative capacity and radiative budget of the tropical troposphere. In the troposphere ozone is produced by photochemical oxidation of carbon monoxide (CO) and volatile organic compounds (VOCs) in the presence of nitrogen oxide radicals. The surface production of ozone does not significantly contribute to the stratospheric ozone. But some stratospheric ozone is transported down into the troposphere and can influence ozone amounts at Earth's surface.

Ozone abundances in the stratosphere and troposphere are determined by the balance between chemical processes that produce ozone and processes that destroy ozone. The balance of production and loss reactions combined with atmospheric air motions determines the global distribution of ozone on time scales of days to many months. Global ozone decreased in the last decades because of the increase in the amounts of reactive gases containing chlorine and bromine in the stratosphere. Total column ozone at any location on the globe is found by measuring all the ozone in the atmosphere directly above that location. Total ozone includes that present in the stratospheric ozone layer and that present throughout the troposphere and is expressed in Dobson unit (denoted “DU”). Typical values vary between 100 and 600 DU over the globe. The global average thickness of ozone layer is only $3 \mathrm{~mm}$ (300 DU). Maximum ozone value is seen at higher latitudes (300 - 500 DU) and the minimum ozone value is noted in the tropical stratosphere ( 250 - $280 \mathrm{DU})$. Even though ozone is produced in the tropical upper stratosphere, it is being transported to higher latitudes and poles by the Brewer Dobson Circulation in the stratosphere.

Radiative property of ozone maintains the thermal structure of the atmosphere and changes in ozone have a significant impact on climate when they occur in the Upper Troposphere/Lower Stratosphere (UT/LS) region. The ozone-weather relationships occur because weather pattern perturb the atmospheric flow not only in the troposphere but also in the lower stratosphere. As a consequence, extra-tropical total ozone values vary in connection with a number of dynamical parameter such as tropospheric temperature [3], the geopotential height [4], the potential vorticity of the lower stratosphere [5], the tropopause height [6] [7], and the tropopuase pressure [8]. From their studies it is concluded that the total ozone in the vertical integrated column show high values when the tropopuase height is low and vice versa [6] [7]. The relationship between total ozone and tropopause height at mid-latitude is approximately linear, with a 15 DU unit change in ozone for $1 \mathrm{~km}$ change in tropopause height. Variation of regional ozone concentration can also result from air advected from different origins. Some studies are available for understanding the behavior of the ozone layer over different latitude region using the14 year TOMS data [9] [10].

The interannual to decadal variability of ozone is related to dynamical behavior of the atmosphere. Interannual variability (IAV) of column ozone depends on its production, distribution and transportation from the source region. The ozone variation in the tropics is mainly controlled by Quasi-Biennial Oscillations (QBO) in lower stratospheric zonal wind. According to them the QBO influences the total ozone variations by $1 \%$ - $2 \%$. Equatorial total ozone change is normally linked with the phases of QBO winds in the lower stratosphere. This cyclic change in wind direction accounts for approximately $3 \%$ of the natural variation in ozone concentration. 
In addition to dynamically induced variations in total ozone, there are sources of ozone variability like 11year solar cycle. The changes in solar ultraviolet spectral irradiance directly modify the production of ozone in the upper stratosphere [11] and hence it is reasonable to expect a solar cycle variation in ozone amounts. Solar constant shows a small variation $(0.1 \%)$, which is more significant in the ultraviolet spectrum than in the visible. Since ozone is created and destroyed by solar UV radiation, there is some correlation of ozone concentration with 11-year sunspot cycles. Sunspots emit high levels of electromagnetic radiation. The increased UV radiation contribute to ozone production. Sunspot variations only account for 2 to $4 \%$ of the total variation in ozone concentrations [12]. Analysis of ground based records extending over 3 - 6 decades indicate the existence of decadal time scale variations of total ozone that is approximately in phase with the solar cycle [13] [14]. A possible mechanism of the interaction between the solar influences on stratospheric ozone chemistry and dynamics was presented based on a study of global climate model [15].

Several studies revealed that natural oscillation of the tropical atmosphere also influences ozone in mid-latitudes [16]-[18] and leads to a differing quantity of transport of stratospheric ozone from the tropical source region to mid-latitudes. It is found that the multi-annual variability in total ozone in the mid-latitude and high latitude in the Northern Hemisphere could be related to changes in the dynamical structure of the atmosphere associated with the North Atlantic Oscillation [8] [19]. The global satellite ozone records since 1979 show evidence for decadal oscillations of total ozone with maximum amplitude ( 2\%) at low latitudes [20]. Many have studied the seasonal cycles [21], trends [19] and interannual variability [22] of tropical ozone. A very few studies are available on long-term variations of total ozone over Indian stations [23]-[25]. Ozone data for the period 1957 to 1994 has been used for the trend analysis of total column ozone over Indian stations [26]. A study establishes that the interannual and intra decadal variation of stratospheric angular momentum is closely associated with total ozone anomalies including the development of the ozone hole in the Antarctica [27]. Studies revealed that several factors are contributing to the interannual variability of ozone, such as dynamical variability makes the largest contribution to IAV over tropical Pacific and maritime continent, where as biomass burning emissions also have a large effect [28].

In this particular study total column ozone for the twelve Indian stations representing the spatial coverage of Indian subcontinent were used to explore the spatial and temporal variability of total column ozone. Detailed method of analysis and inferences are presented in the in the following sections of this paper.

\section{Materials and Methods}

Total Ozone Mapping Spectrometer (TOMS) instrument onboard on Nimbus-7 Satellite (Nimbus-7 was launched on October 24, 1978 from National Aeronautics and Space Administration (NASA and the measurements began on October 31, 1978 and did end on May 6, 1993) with sun-synchronous orbit can provide daily maps of total ozone except where the Earth's atmosphere is shaded by polar night. Total Ozone Mapping Spectrometer was designed to produce accurate global estimates of total column ozone. It can also detect $\mathrm{SO}_{2}(\mathrm{gas}), \mathrm{H}_{2} \mathrm{SO}_{4}$ (Sulphate) aerosols in the stratosphere and UV absorbing aerosols (smoke, dust) over land and ocean. This instrument measures solar irradiance and radiance backscattered from earth's atmosphere at six wavelengths extending from approximately 310 to $380 \mathrm{~nm}$. Total column ozone is derived from the differential absorption of scattered sunlight in the ultraviolet region. Ozone content or density is calculated by taking the ratios of two wavelengths (312 nm and $331 \mathrm{~nm}$ ) where one wavelength is strongly absorbed by ozone while the other is weakly absorbed. Total Ozone Mapping Spectrometer makes 35 measurements every 8 seconds, each covering 50 - $200 \mathrm{~km}$ on the ground except areas near the poles. These individual measurements vary typically between 100 and 650 Dobson units (DU). The TOMS data version 7 are available as (a) gridded daily, (b) gridded monthly average, (c) GIF images, (d) overpass data and (e) zonal means [29].

Average instrumental calibration of long term drift of TOMS Nimbus-7 data is believed to be less than $1 \%$ per decade. The absolute error is \pm 3 percent, the random error is \pm 2.0 percent $(1 \sigma)$ and the uncertainty in the drift for 14 years is \pm 1.5 percent (though somewhat higher at high latitudes) for the measurements of ozone. Validation of 14.5 years of Nimbus-7 TOMS version 7 ozone data was done by comparing with the Dobson network [29]. Total Ozone Mapping Spectrometer products are freely available in Goddard Space Flight Laboratory, (USA) from the website (http://toms.gsfc.nasa.gov) for the research purposes and need to acknowledge. Daily over pass total column ozone over twelve Indian stations and daily gridded column ozone data over tropics 
$\left(12.5^{\circ} \mathrm{S}\right.$ to $\left.12.5^{\circ} \mathrm{N}\right)$ for the period $1979-92$ are considered for the present study. Figure 1 represent the Indian stations selected on the basis of availability of TCO from south to north latitudes for the period 1979-1992. To study the variability of TCO with phases of QBO, zonal wind at $20 \mathrm{hPa}$ from National Centers for Environmental Prediction/National Centre for Atmospheric Research (NCEP/NCAR) reanalysis [30] are also used along with the gridded column ozone from the TOMS instrument.

\subsection{Factor Analysis}

Factor analysis method is a multivariate analysis technique used for the spatial analysis of total column ozone between stations. This statistical method concerns the reduction of a set of observable variables in terms of a small number of latent factors. The underlying assumption of factor analysis is that there exist a number of unobserved latent variables (or factors) that account for the correlation among observed variables, such that if the latent variables are held constant, the partial correlations among observed variables all become zero. The "Eigen values greater than one" rule has been used to select the number of significant factors (Kaiser-Guttman rule). It states that the number of factors to be extracted should be equal to the number of factors having an Eigen value (variance) greater than 1 . The rationale for choosing this particular value is that a factor must have variance at least as large as that of a single standardized original variable [31]-[33].

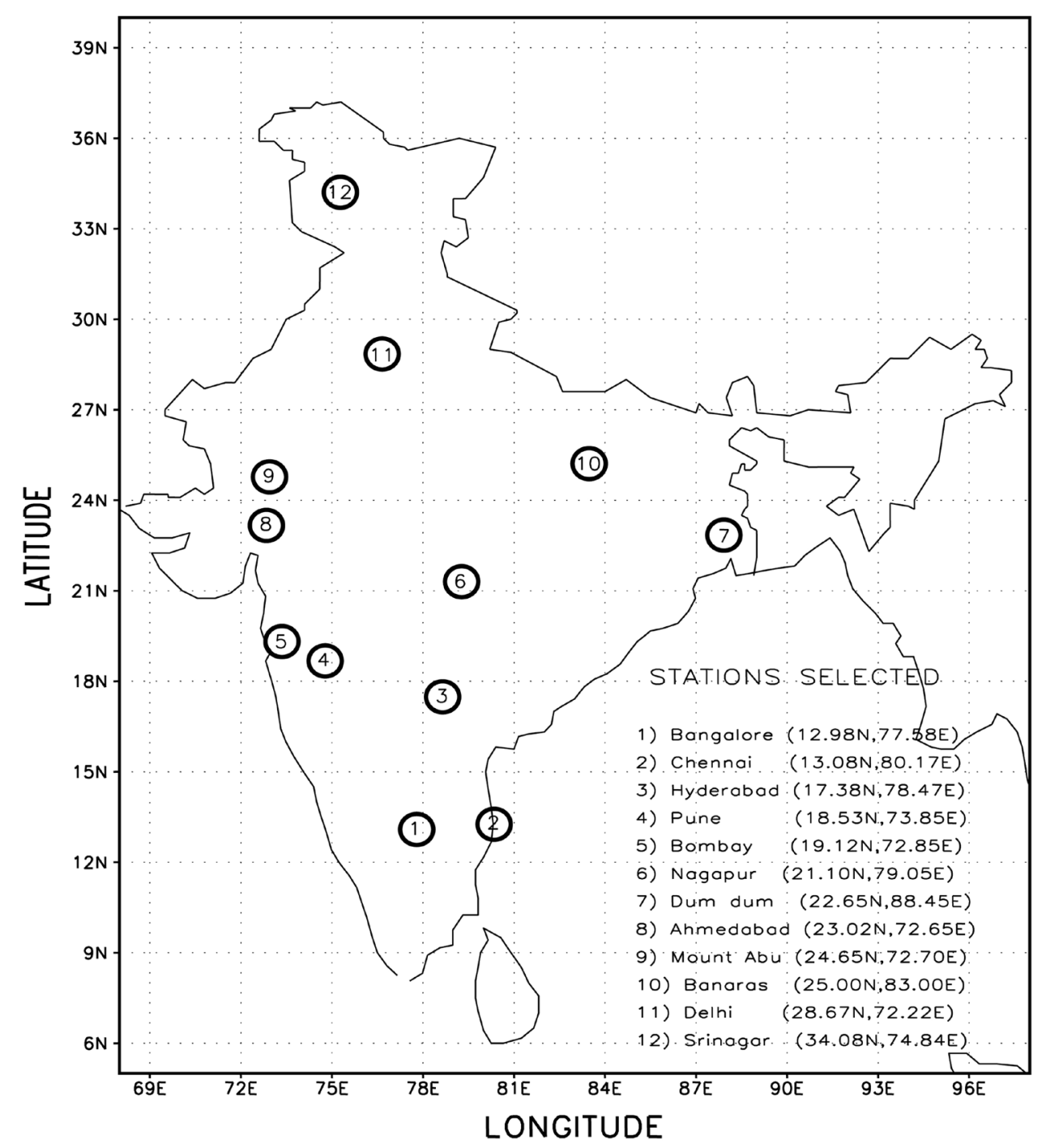

Figure 1. Stations selected over the Indian subcontinent for the study of TCO. 


\subsection{Morlet Wavelet Transforms}

Morlet wavelet technique which is an advanced and powerful tool in the time-frequency analysis has been used to understand the periodicity of the total column ozone. Generally, time frequency analysis is performed using Fourier Transform (FT) method for frequency components over the whole period. But it does not give the change in frequency response with time. In order to overcome the limitations of Fourier Transform there is Short-Time Frequency Transform (STFT), which uses a window function to catch the frequency component in a time interval. In STFT the resolution is fixed because its window width is fixed, but difficulty still exists in simultaneous measurement of time domain and frequency domain according to the uncertainty principle. Hence a multi-resolution concept such as a high time resolution for observing the high frequency signals and a high frequency resolution for observing low frequency signal components is required. Wavelet transform method achieves this aim by changing the location and scaling of the mother wavelet, which is the window function in the wavelet transform. Wavelet transform employing a window with variable width, can capture both the short duration high frequency and long duration short frequency signals simultaneously. This method is more flexible than STFT and hence widely used for the analysis of transients, aperiodicity and other non-stationary signal features.

Mathematically, a Wavelet Transform (WT) decomposes a signal $s(t)$ in terms of some elementary function $\psi_{b, a}(t)$ derived from a "Mother Wavelet” or “Analyzing Wavelet” $\psi(t)$ by dilation and translation:

$$
\psi_{b, a}(t)=\frac{1}{(a)^{1 / 2}} \psi\left(\frac{t-b}{a}\right)
$$

where " $b$ " denotes the position (translation) and $a(>0)$ the scale (dilatation) of the wavelet; $\psi_{b, a}(t)$ are called "daughter wavelets" or, simply, "wavelets". An energy normalization factor $(a)^{-1 / 2}$ in Equation (1) keeps the energy of the daughter wavelets the same as the energy of the mother wavelet. The wavelets in which no restriction is placed on the value of the dilation and translation parameters are called continuous wavelets and have a symmetric structure. One of the most widely used continuous wavelets is the complex Morlet wavelet that consists of a plane wave modified by a Guassian envelope. In order to study the periodicities in the wavelike signals the Morlet wavelet is the most popular complex wavelet transform, with a mother wavelet defined as

$$
\psi(t)=e^{i k_{\Psi} t} e^{-|t|^{2} / 2}
$$

Continuous wavelets are not orthogonal to one another. So there is no one to one relationship between the individual wavelet coefficients and the specific percentage of the variance in each frequency range [34].

In the present work the interannual variability in the total column ozone has been studied by means of Morlet wavelet analysis using the TCO anomaly for the period January 1979 to August 1993 (128 months). Power spectrum method is also used to test the significance of different periodic oscillations obtained through the Morlet wavelet analysis.

\section{Results and Discussion}

Total column ozone varies both spatially and temporally over the globe. Majority of the atmospheric ozone is produced in the tropical upper stratosphere and it is being transported to higher latitudes by a stratospheric circulation called Brewer Dobson Circulation (BDC). There is a rising motion in the tropics from the troposphere to the stratosphere with poleward transport and descending motion in the stratosphere at middle and polar latitudes [35] [36]. In this work a detailed analysis was made to understand the spatial and temporal variability of total column ozone over the Indian subcontinent during the period 1979 to 1992 using the Nimbus-7 TOMS over pass total column ozone.

\subsection{Spatial Variability of Total Column Ozone}

Variability of total column ozone over different stations depends on latitude, season, transportation and other inherent variability (natural, anthropogenic, spatial/temporal) of multivariate origin. For the spatial variability of TCO a multivariate analysis technique (Factor Analysis) is used, which reduces multi variables to few derived variables (factors) which contribute dominantly to the total variability. Factor analysis is a standard technique in multivariate analysis which removes redundancy or duplication from a set of correlated variables [32]. The main 
goal of the factor analysis is the control of conformity of a priory given factor structure to the experimental data, and the analysis of quantitative differences between tests. Factors are formed that are relatively independent of one another and represents correlated variables with a smaller set of "derived variables". Mathematical steps of this method are beyond the scope of this paper.

The spatial correlations of TCO between different stations obtained by factor analysis method are depicted in Table 1. Based on the similarity in TCO variability these stations are grouped into two clusters (Eigen value greater than 1). Eight stations (Hyderabad, Pune, Bombay, Nagpur, Dum Dum, Ahmedabad, Mount Abu and Banaras) out of twelve come under Group I, where the first factor is the primary loading, i.e., first factor greater than second factor. Remaining four stations representing low latitude (Bangalore and Chennai) and high latitude (Delhi and Srinagar) fall under Group II, where primary loading is second factor, i.e., second factor is greater than the first factor. Spatial correlation of TCO between stations shows high positive correlation with nearby stations and the correlation values decrease from 0.9 to 0.32 for far away stations (south to north stations as in Table 1).

\subsection{Temporal Variability of Total Column Ozone}

A detailed study has been made to understand the temporal variability of TCO over different stations in the Indian subcontinent. Total column ozone varies with seasons and latitudes for the period of study (1979-1992). Temporal variability of TCO is mainly related to dynamical behavior of the atmosphere. Figure 2 shows the climatology of TCO (14 year) over different stations with increasing latitude of the Indian subcontinent during the period 1979-1992. From Figure 2 it is noted that TCO concentration is maximum during the monsoon season (June-September) for stations with latitudes $<20^{\circ} \mathrm{N}$ (tropical stations). For stations with latitudes $>20^{\circ} \mathrm{N}$ (subtropical stations) such as Delhi and Srinagar, the maximum value of TCO is observed in the pre-monsoon season. This change indicates the role of monsoon and pre monsoon circulations in the TCO distribution. From the 14 year climatology, the annual average of TCO for tropical stations is found to be about 265 DU with a maximum of 283 DU observed in the month of June and a minimum of 247 DU recorded during January. Accordingly the difference between the maximum and minimum values of TCO for the tropical station is observed to be 36 DU. On the other hand for subtropical stations $\left(>20^{\circ} \mathrm{N}\right.$, latitudes) the annual average was $280 \mathrm{DU}$ with a maximum value of 296 DU recorded during March-May and minimum value of 256 DU during NovemberJanuary with a difference of 40 DU between the maximum and minimum. A difference of 15 DU is noted in the annual average of TCO concentrations between the tropical and subtropical stations with a difference of 10 DU

\begin{tabular}{cccccccccccccc}
\multicolumn{1}{l}{ Table 1. Spatial correlations of TCO between stations. } \\
\hline Stations & BNGR & CHNN & HYDE & PUNE & BMBY & NGPR & DUMM & AHMD & MUNT & BNRS & DELH & SRNR \\
\hline BNGR & 1 & 0.96 & 0.833 & 0.7 & 0.758 & 0.7 & 0.63 & 0.645 & 0.61 & 0.59 & 0.49 & 0.32 \\
CHNN & 0.96 & 1 & 0.815 & 0.7 & 0.751 & 0.69 & 0.625 & 0.643 & 0.61 & 0.59 & 0.51 & 0.35 \\
HYDE & 0.833 & 0.815 & 1 & 0.91 & 0.961 & 0.93 & 0.866 & 0.864 & 0.81 & 0.8 & 0.65 & 0.46 \\
PUNE & 0.7 & 0.695 & 0.909 & 1 & 0.944 & 0.93 & 0.875 & 0.92 & 0.87 & 0.84 & 0.72 & 0.53 \\
BMBY & 0.758 & 0.751 & 0.961 & 0.94 & 1 & 0.96 & 0.897 & 0.933 & 0.88 & 0.85 & 0.72 & 0.52 \\
NGPR & 0.699 & 0.69 & 0.925 & 0.93 & 0.96 & 1 & 0.954 & 0.954 & 0.92 & 0.92 & 0.76 & 0.52 \\
DUMM & 0.63 & 0.625 & 0.866 & 0.87 & 0.897 & 0.95 & 1 & 0.906 & 0.88 & 0.93 & 0.75 & 0.49 \\
AHMD & 0.645 & 0.643 & 0.864 & 0.92 & 0.933 & 0.95 & 0.906 & 1 & 0.98 & 0.93 & 0.83 & 0.59 \\
MUNT & 0.606 & 0.609 & 0.811 & 0.87 & 0.884 & 0.92 & 0.876 & 0.978 & 1 & 0.94 & 0.91 & 0.66 \\
BNRS & 0.589 & 0.593 & 0.796 & 0.84 & 0.853 & 0.92 & 0.934 & 0.931 & 0.94 & 1 & 0.88 & 0.59 \\
DELH & 0.486 & 0.505 & 0.647 & 0.72 & 0.722 & 0.76 & 0.748 & 0.832 & 0.91 & 0.88 & 1 & 0.8 \\
SRNR & 0.323 & 0.352 & 0.463 & 0.53 & 0.524 & 0.52 & 0.487 & 0.586 & 0.66 & 0.59 & 0.8 & 1 \\
\hline
\end{tabular}



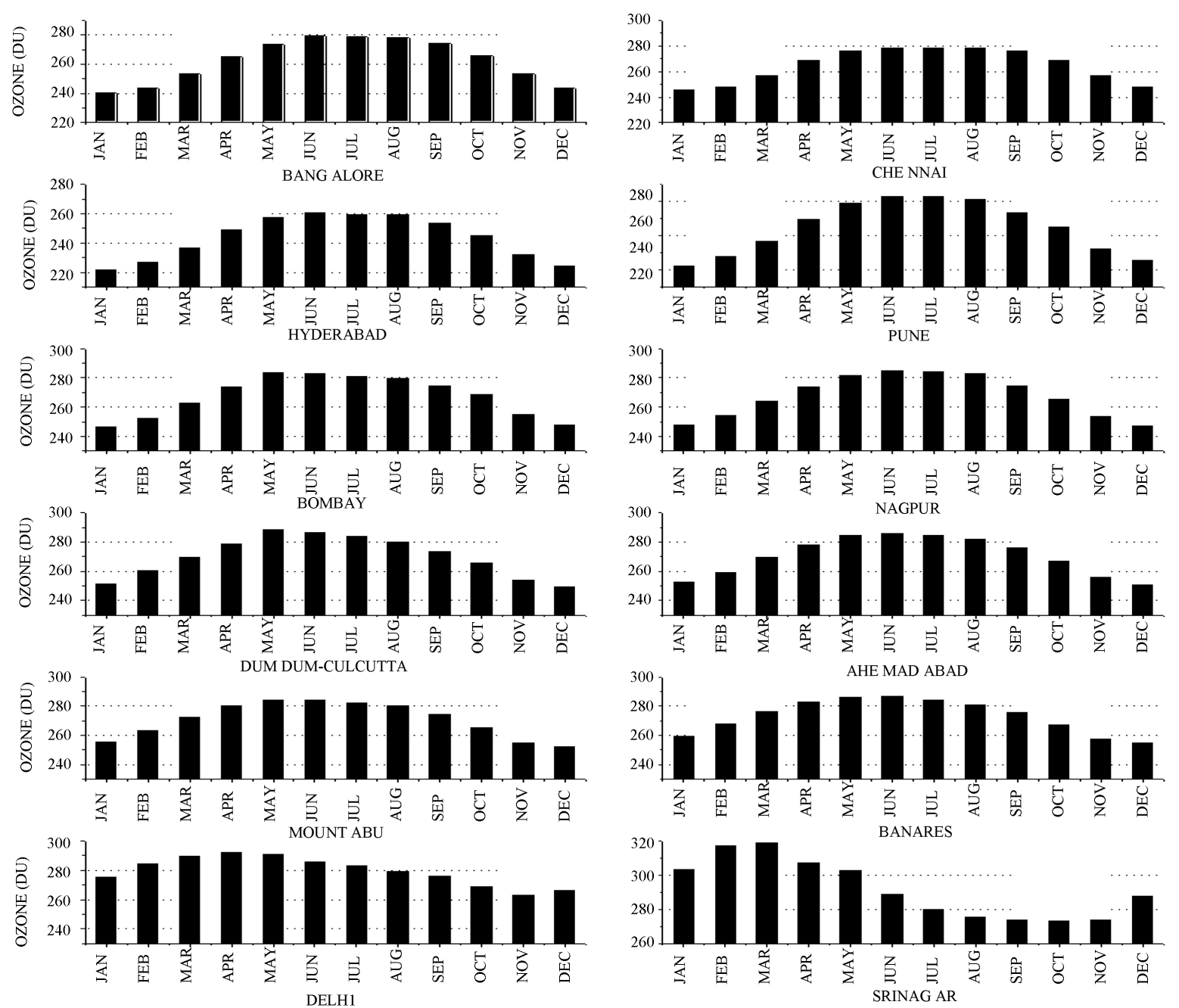

Figure 2. Total column ozone climatology (in dobson unit) for the stations (1979-1992).

in the maximum values and 9 DU in the minimum values.

\subsubsection{Interannual Variability of Total Column Ozone}

Total column ozone shows interannual (year to year) variability between tropical and subtropical stations selected over the Indian region. Figure 3 and Figure 4 show the interannual variability of TCO for tropical stations and subtropical stations using the TCO anomaly for the period 1979-1992. In Figure 3 TCO anomaly shows an extreme negative value of -15 DU in the year 1985 for the tropical stations. It is interesting to note that a drastic reduction in the ozone concentration was discovered over Antarctica in the same year [37]. This coincidence proves the global reduction in TCO production and distribution. A negative trend of TCO anomaly is noted during the period 1983 to 1985 over the tropical stations and a maximum positive value 12 DU is observed in the year 1981 for all the tropical stations (see Figure 3). During the period (1979-1992) only at one occasion the TCO anomaly dropped below -20 DU (in the year 1985) and at two occasions it peak about 12 DU (in the year 1981 and 1992) over Bangalore. Total column ozone anomaly drops below -15 DU over Hyderabad and Pune at four times (in the years 1980, 1983, 1985 and 1987). This is a clear indication of IAV of TCO over these stations.

Figure 4 shows the TCO anomaly over the subtropical stations with latitudes $>20^{\circ} \mathrm{N}$. A reduction of TCO anomaly greater than -25 DU is noted during the year 1985 as in the case of tropical stations. A reduction of -40 DU is noted in TCO anomaly over Srinagar in the years 1985, 1986 and 1988 and over Delhi in 1985 and 1988. There was no significant IAV in TCO over the subtropical stations after 1988. During the period 1979 to 1984 almost all subtropical stations recorded a positive TCO anomaly ( 15 DU); for Delhi and Srinagar the TCO 


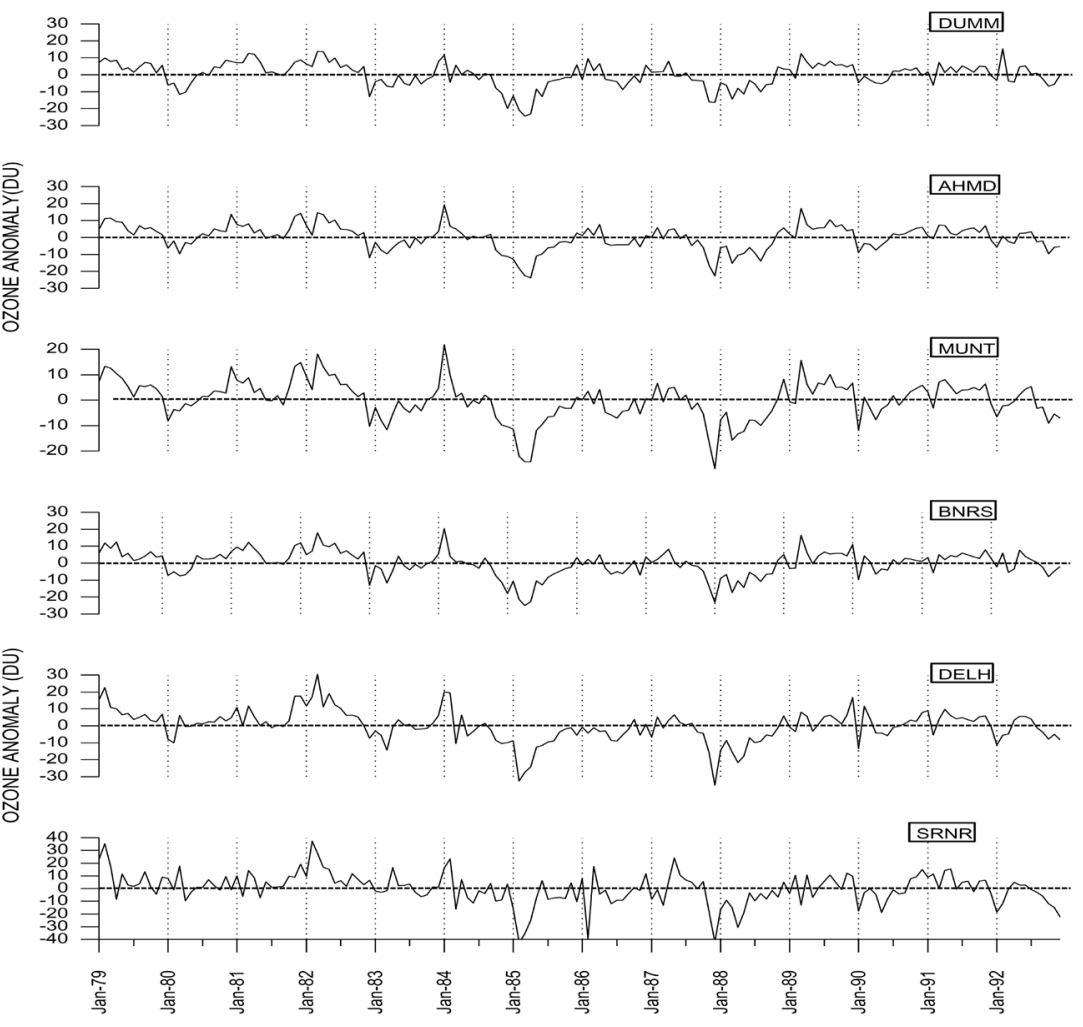

Figure 3. Total Column Ozone anomaly (in DU) over tropical stations (1979-1992).
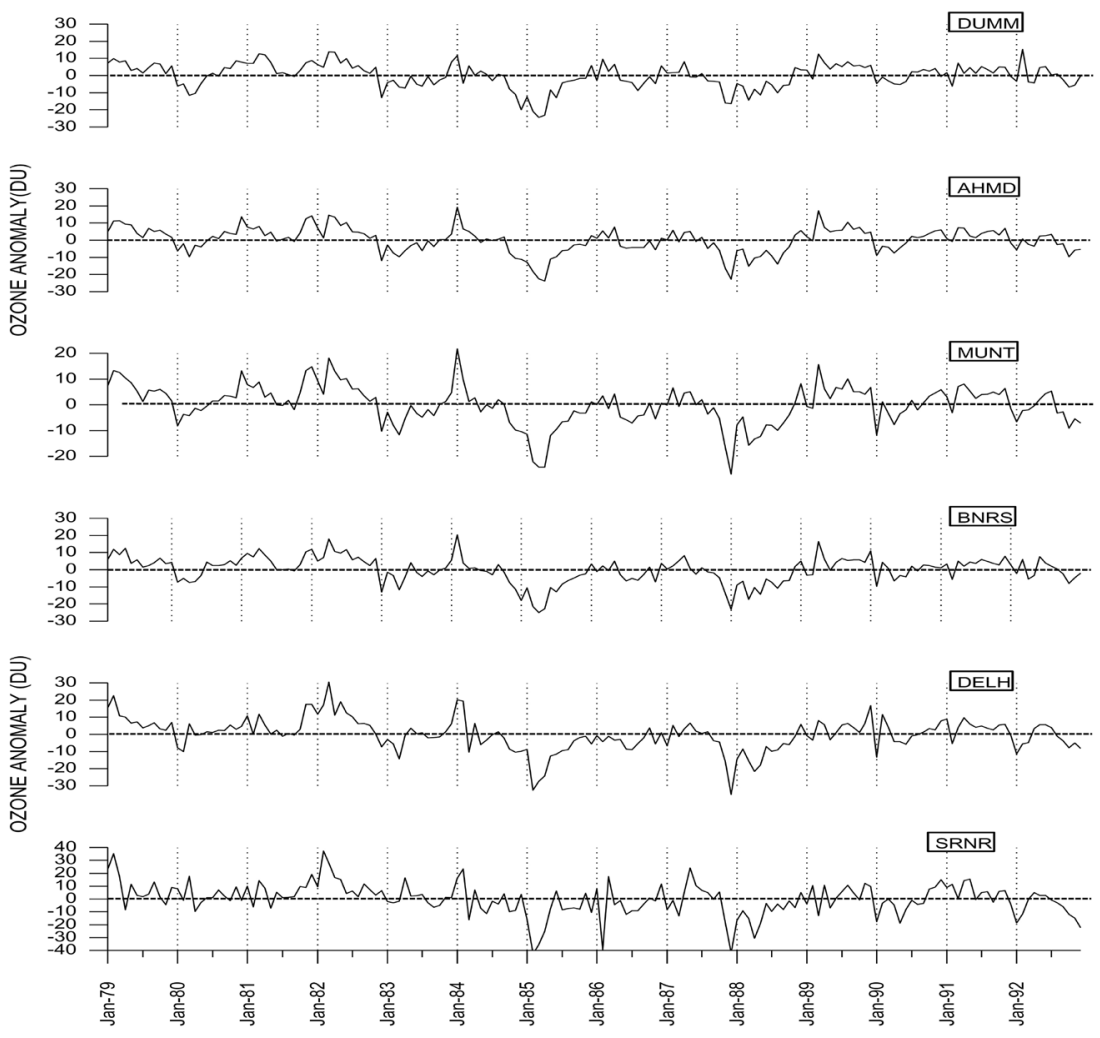

Figure 4. Total Column Ozone anomaly (in DU) over subtropical stations (1979-1992). 
anomaly attained a maximum of 30 DU in the year 1982.

To understand the small scale periodicity present in total column ozone over these stations an advanced statistical tool, Morlet wavelet is employed. In this method the time series data of TCO decomposes for all periodicities including smaller to higher periods. Anomaly value of TCO for all stations from January 1979 to August 1989 is used to obtain the wavelet spectrum of TCO and the method of analysis (Morlet wavelet) is being discussed in data and methodology [34]. Figures 5(1)-(12) show the Morlet wavelet spectrum indicating different periodicity of oscillations present in the TCO for the twelve stations from the low latitude (Bangalore $12.98^{\circ} \mathrm{N}$, $77.58^{\circ} \mathrm{E}$ ) to high latitude (Srinagar, $34.08^{\circ} \mathrm{N}, 74.84^{\circ} \mathrm{E}$ ). The y-axis is marked with all possible periodicities with maximum period taken 64 months for the 128 data points. The x-axis gives time series of TCO anomaly from January 1979 to August 1989 (128 months). The positive and negative wavelet coefficients are shaded with yellow and blue color respectively in the figure. From these wavelet spectra we got two major oscillations in TCO, one with a periodicity varying from 16 to 18 months and the other with 26 to 32 months (approximately the periodicity of quasi-biennial oscillation) for all the stations apart from the annual oscillations (12 months periodicity). The small scale oscillations with periodicity less than twelve months can only be treated as noises present in the total ozone variation. In the wavelet analysis the spectrum shows an indication for the 11-year sunspot cycle in the total ozone anomaly for higher periodicity variations. But we cannot confirm authentically the signal of 11-year solar cycle in total ozone anomaly with this short period data set (1979-1992). Shaded contour in yellow color (positive wavelets coefficients) and blue color (negative wavelets coefficients) represents the intensity of

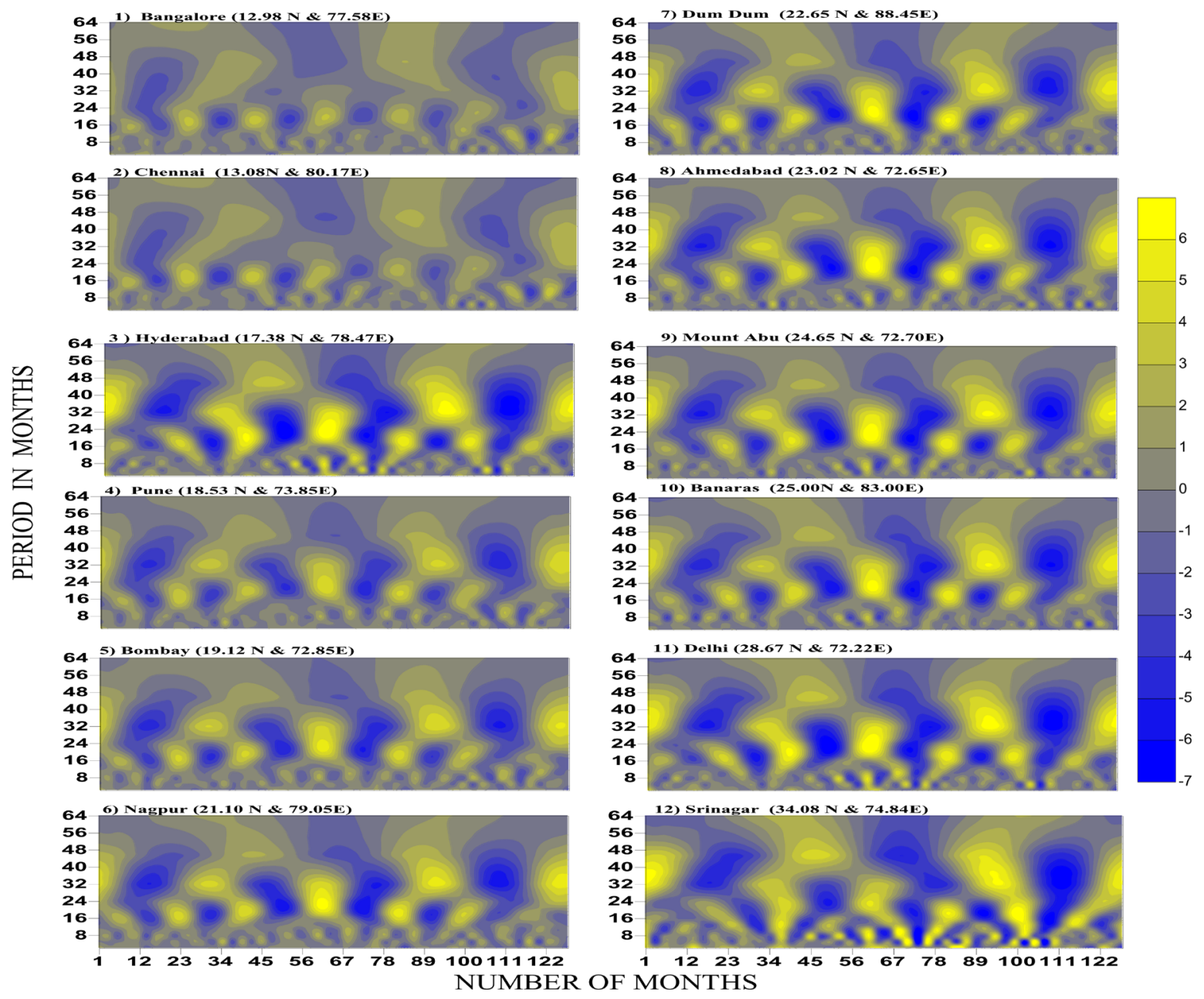

Figure 5. Morlet Wavelet Spectrum of TCO anomaly for the tropical and subtropical stations from January 1979 to August 1989 (128 months). Wavelets coefficients are shaded blue color (Negative Wavelets coefficients) and yellow colour (Positive Wavelet coefficients) represent the different periods in total column ozone. 
oscillation with different periodicity over the time period.

The level of significance of these oscillations in total ozone obtained from the Morlet wavelet is tested with the Power Spectrum method. Figure 6 represents the Power Spectra of total ozone anomaly for the twelve In-
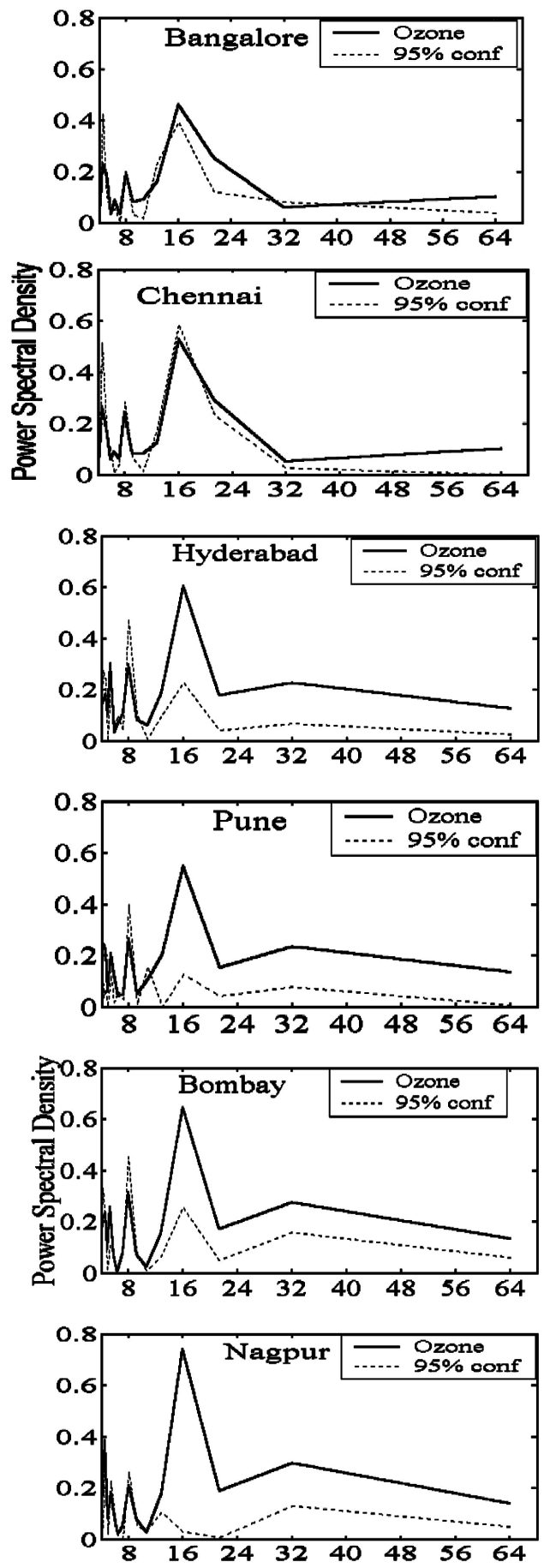
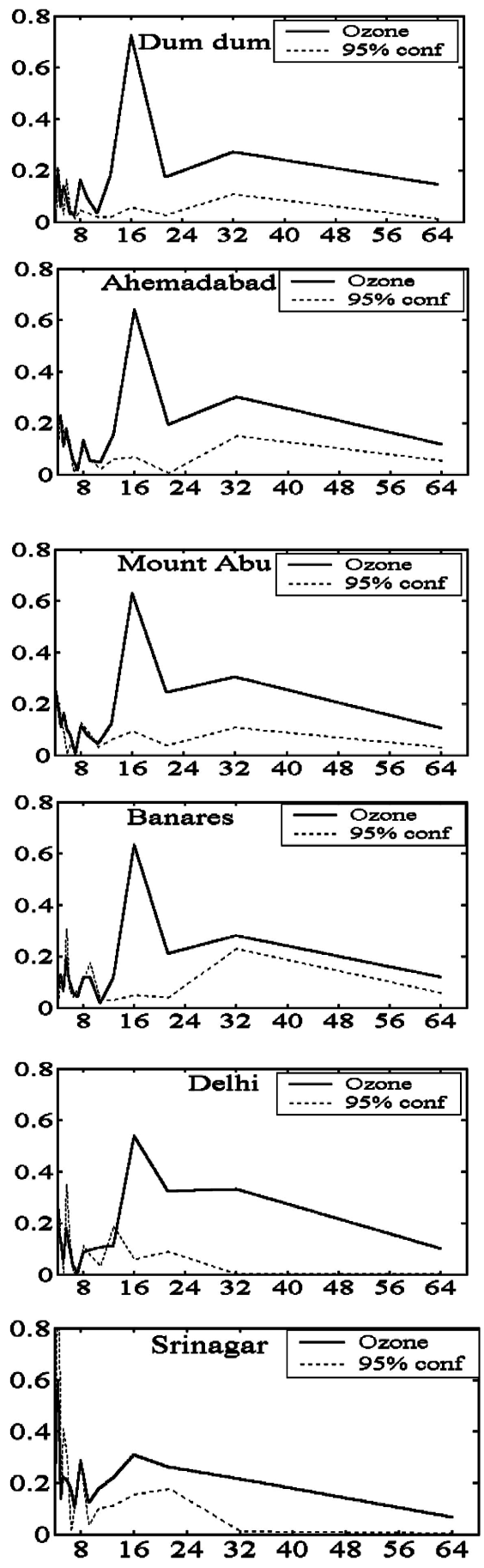

\section{Number of Months}

Figure 6. Power spectrum shows the significanc of oscillations in TCO anomaly for the stations. Dotted line represents $95 \%$ level of confidnece and solid line represnts the oscillations present in the TCO for the period January 1979 to August 1989 (128 months). 
dian stations corresponding to the wave spectrum obtained from the wavelet analysis. The power spectral density is marked on the $\mathrm{y}$-axis and the period (in months) along the $\mathrm{x}$-axis. The dotted line represents the $95 \%$ significant level and the solid line represents the oscillation present in the TCO. Here it is seen that 16 to 18 months oscillation is more dominant in the central Indian stations than in low and high latitude stations. It can also be seen that for low latitude stations (Bangalore and Chennai) and high latitude stations (Delhi and Srinagar) the power spectral density of column ozone is very small for 16 to 18 months oscillations. Similarly the QBO oscillations are not that significant for the above low latitude and high latitude stations compared with the central Indian stations (Hyderabad, Pune, Bombay, Nagpur, Dum dum, Ahemadabad, Mount Abu and Banares). Hence there is a possibility that the interannual variability of total ozone do not completely depends on latitudinal effect and the man made activities, but the dynamical factors (Brewer-Dobson Circulation) may also influence the tropical stratospheric circulation of the upper troposphere and lower stratospheric region of the atmosphere. It is also found that the 16 - 18 months mode of oscillation is more significant than the QBO (28 - 32 months) mode.

\subsubsection{Quasi-Biennial Oscillation in Tropical Total Column Ozone}

The QBO is characterized by downward propagation of alternating westerly and easterly zonal wind regimes in the equatorial lower stratosphere with a period varying approximately from 28 to 30 months [38]. The QBO arises from the interaction of vertically propagating equatorial waves acting on the zonal mean flow [39]. The effect of the QBO can be seen on trace gases and temperature, both of which vary with the phase of the wind shear.

There are studies available for establishing the connection of stratospheric QBO and interannual variation of ozone. In the polar latitudes ozone concentration increases with easterly and decreases with westerly phases of equatorial stratospheric QBO and the model results are in good agreement with the observations [40]-[42]. Equatorial total ozone change is normally linked with the phases of QBO winds in the lower stratosphere. This cyclic change in wind direction accounts for approximately $3 \%$ of the natural variation in ozone concentration [43]-[45]. Garcia et al. [39] showed a relationship between ozone holes developed in the Antarctic and the equatorial QBO. Another study examined the relation of total ozone variations in the extra tropics with the QBO of zonal wind of the lower stratosphere at Singapore [40].

Gridded total column ozone anomaly for the tropical region between latitudes $12.5^{\circ}$ South to $12.5^{\circ}$ North from the Nimbus-7 TOMS and zonal wind anomaly at $20 \mathrm{hPa}$ from the NCEP/NCAR reanalysis [30] for 14-year period (1979-1992) were used to study the phase relation of QBO with tropical column ozone. Figure 7 shows the link between phases of equatorial stratospheric QBO and total column ozone variability over the tropics. The upper panel in Figure 7 shows the total column ozone anomaly for the period 1979-1992 with a contour interval of 3 Dobson Unit for the latitudes $12.5^{\circ}$ South to $12.5^{\circ}$ North. The bottom panel in the figure shows the zonal wind anomaly at $20 \mathrm{hPa}$ for the above period with contour interval $5 \mathrm{~ms}^{-1}$. It is very interesting to note that when the stratospheric QBO is in easterly phase (shaded in blue color in the bottom panel) the corresponding total column ozone value shows a negative anomaly (shaded in blue color in the upper panel) and when the QBO in westerly phase (shaded in yellow color in bottom panel) there is positive anomaly (shaded in yellow color top panel) of TCO noted during the period of study. There is variability in the periodicity of ozone QBO noted over this period. Depending on the strength of the easterly (westerly) phases of QBO, corresponding decrease (increase) of ozone anomaly were noted. The westerly phase of QBO reaches a value of $15 \mathrm{~ms}^{-1}$ during the year 1985 and 1990 with corresponding ozone anomaly 12 DU. During the year 1984 and 1987 the easterly phase of QBO was very strong and corresponding ozone anomaly reached a negative value of -12 DU. Hence from the study it is concluded that the concentrations and variability of tropical ozone strongly depends on the strength of the QBO phase over the tropics. But there is opposite relation exist for the column ozone over higher latitude with equatorial stratospheric quasi-biennial oscillation [40]-[42].

\section{Conclusion}

The spatial and temporal variability analysis of total column ozone over the Indian subcontinent using the Nimus-7 TOMS data revealed many interesting results. From the analysis for tropical stations $\left(<20^{\circ} \mathrm{N}\right)$, the TCO is maximum during monsoon season with peak value of TCO in the month of June and that for the subtropical stations $\left(>20^{\circ} \mathrm{N}\right)$ maximum value of TCO in the pre monsoon months. There noted a difference of 15 DU in the annual average TCO between tropical and subtropical stations. Large reduction in TCO was noted over the In- 

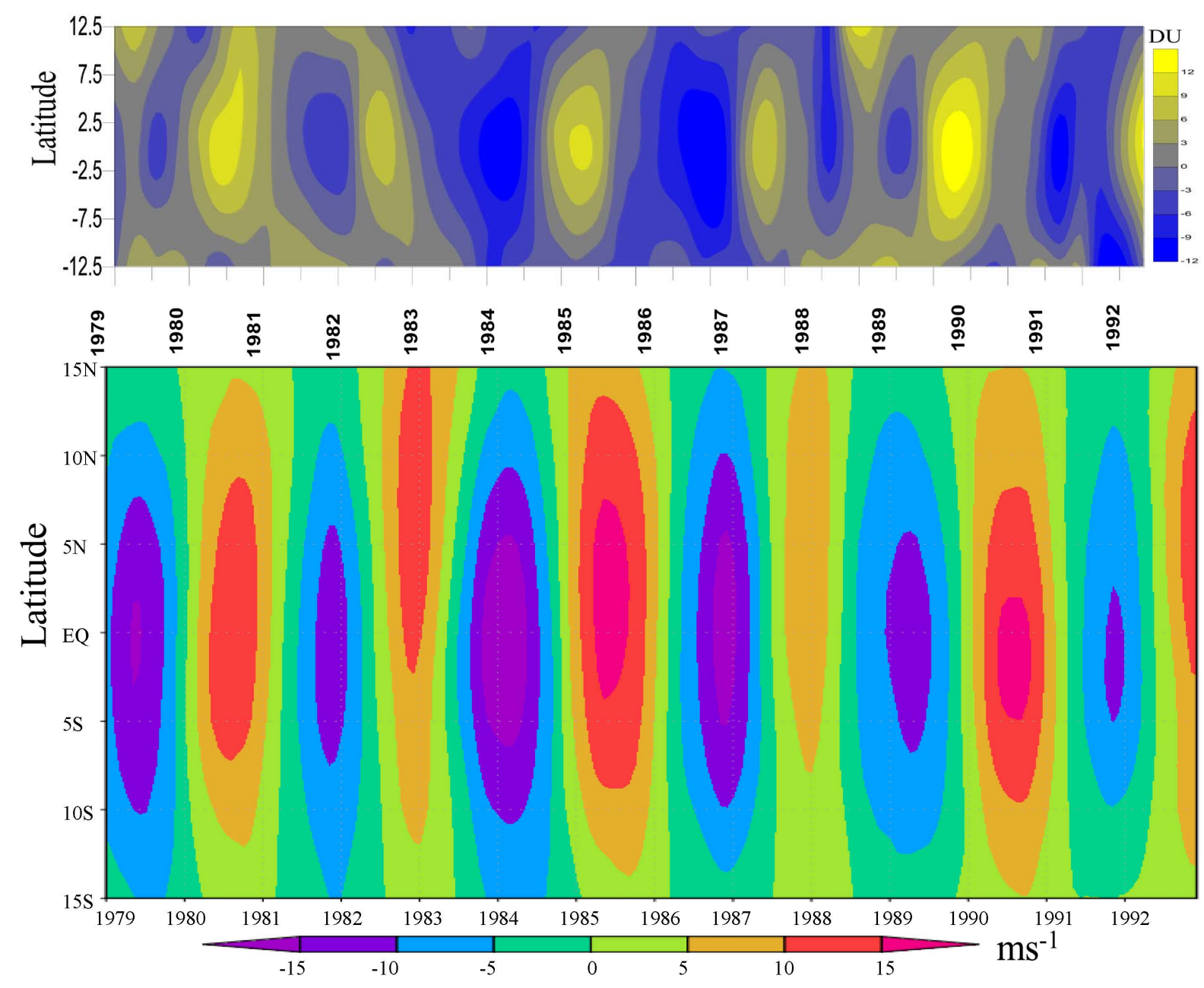

Figure 7. Quasi-Bienniel Oscillations in TCO anomaly over tropics with contour interval 3 DU ( Upper Panel) and QBO for the zonal wind anonaly at $20 \mathrm{hPa}$ with contour interval $5 \mathrm{~ms}^{-1}$ (Botom panel) for the period 1979-1992.

dian subcontinent in the year 1985, the very year in which ozone hole was discovered over Antarctica. The IAV study of TCO, using the Morlet wavelet and Power spectrum, reveals two major oscillations with periodicity between 16 - 18 months and between 26 - 32 months (quasi-biennial oscillation) over all the stations and it is more significant over the central Indian stations compared to the low latitude (Bangalore and Chennai) and high latitude (Delhi and Srinagar) stations. The oscillations obtained through the Morlet wavelet method is tested with power spectrum analysis and found that the oscillations are found to be significant at $95 \%$ above the level of confidence. The oscillation in TCO between 16 to 18 months is more prominent compared to quasi-biennial mode over Indian subcontinent. We suppose that the interannual variability of total column ozone may depend on the dynamical factors (atmospheric circulations) other than the latitudinal effect and increase of CFC's due to the man made activities. The spatial correlation (factor analysis) of TCO between stations shows similar type of TCO variability over eight stations located in central India (Group I). There is another class (Group II) which include two low latitude stations (Bangalore and Chennai) and two high latitude stations (Delhi and Srinagar) shows similar type of variability in TCO due to reasons other than the Group I stations. This can be attributed to how much the variable under each factor (such as latitude, season and transport) contributes to the total variability of TCO. Tropical total column ozone variability is linked with the phases of equatorial stratospheric QBO in such a way that total column ozone concentration is less during the easterly and high during the westerly phases of QBO and there is opposite relation exist between the equatorial stratospheric QBO and TCO variability over the high and polar latitudes. 


\section{Acknowledgements}

Author is grateful to NASA Goddard Space Flight Center for made available Nimbus-7 TOMS products in public domain. Author is also indebted to Indian Space Research Organization and SERB DST for the support.

\section{References}

[1] Lacis, A.A., Wuebbles, D.J. and Logan, J.A. (1990) Radiative Forcing of Climate by Changes in the Vertical Distribution of Ozone. Journal of Geophysical Research, 95, 9971-9981. http://dx.doi.org/10.1029/JD095iD07p09971

[2] Forster, P. and Shine, K. (1997) Radiative Forcing and Temperature Trends from Stratospheric Ozone Changes. Journal of Geophysical Research, 102, 10841-10855. http://dx.doi.org/10.1029/96JD03510

[3] Staehelin, J., Kegel, R. and Harris, N.R.P. (1998) Trend Analysis of Homogenized Total Ozone Series of Arosa (CH), 1926-1996. Journal of Geophysical Research, 103, 8389-8399. http://dx.doi.org/10.1029/97JD03650

[4] Ziemke, J.R., Chandra, S., McPeters, R.D. and Newman, P.A. (1997) Dynamical Proxies of Column Ozone with Applications to Global Trend Models. Journal of Geophysical Research, 102, 6117-6129. http://dx.doi.org/10.1029/96JD03783

[5] Vaughan, G. and Price, J.D. (1991) On the Relation between Total Ozone and Meteorology. Quarterly Journal of Royal Meteorological Society, 117, 1281-1298. http://dx.doi.org/10.1002/qj.49711750208

[6] Schubert, S.D. and Munteanu, M.-J. (1988) An Analysis of Tropopause Pressure and Total Ozone Correlations. Monthly Weather Review, 116, 569-582. http://dx.doi.org/10.1175/1520-0493(1988)116<0569:AAOTPA>2.0.CO;2

[7] Steinbrecht, W., Claude, H., Köhler, U. and Hoinka, K.P. (1998) Correlations between Tropopause Height and Total Ozone: Implications for Long-Term Changes. Journal of Geophysical Research: Atmospheres (1984-2012), 103, 1918319192.

[8] Appenzeller, C., Weiss, A. and Staehelin, J. (2000) North Atlantic Oscillation Modulates Total Ozone Winter Trends. Geophysical Research Letters, 27, 1131-1134. http://dx.doi.org/10.1029/1999GL010854

[9] Herman, J.R. and Larko, D. (1994) Nimbus-7/TOMS-November 1, 1978 to May 6, 1993: Low Ozone Amounts During 1992-1993 from Nimbus-7 and Meteor-3 Total Ozone Mapping Spectrometer. Journal of Geophysical Research, 99, 3483-3496. http://dx.doi.org/10.1029/93JD02594

[10] Randel, W.J. and Cobb, J.B. (1994) Coherent Variations of Monthly Mean Total Ozone and Lower Stratospheric Temperature. Journal of Geophysical Research, 99, 5433-5447. http://dx.doi.org/10.1029/93JD03454

[11] Brasseur, G.P., Hauglustaine, D.A., Walters, S., Rasch, P.J., Müller, J.-F., Granier, C. and Tie, X.X. (1998) MOZART: A Global Chemical Transport Model for Ozone and Related Chemical Tracers: Model Description. Journal of Geophysical Research, 103, 28265-28289. http://dx.doi.org/10.1029/98JD02397

[12] Willett, H.C. (1962) The Relationship of Total Atmospheric Ozone to the Sunspot Cycle. Journal of Geophysical Research, 67, 661-670.

[13] Angell, J.K. (1989) On the Relation between Atmospheric Ozone and Sunspot Number. Journal of Climate, 2, 14041416. http://dx.doi.org/10.1175/1520-0442(1989)002<1404:OTRBAO >2.0.CO;2

[14] Zerefos, C.S., Tourpali, K., Bojkov, B.R. and Balis, D.S. (1997) Solar Activity—Total Column Ozone Relationship: Observations and Model Studies with Heterogeneous Chemistry. Journal of Geophysical Research, 102, 1561-1569. http://dx.doi.org/10.1029/96JD02395

[15] Shindell, D., Rind, D., Balachandran, N., Lean, J. and Lonergan, P. (1999) Solar Cycle Variability, Ozone, and Climate. Science, 284, 305-308. http://dx.doi.org/10.1126/science.284.5412.305

[16] Zerefos, C.S., Bais, A.P., Ziomas, I.C. and Bojkov, R.D. (1992) On the Relation and Elnino-Southern Oscillation in the Revised Dobson Total Ozone Records. Journal of Geophysical Research, 97, 10135-10144. http://dx.doi.org/10.1029/92JD00508

[17] Bowman, K.P. (1989) Global Patterns of the Quasi-Biennial Oscillation in Total Ozone. Journal of Atmospheric Science, 46, 3328-3343. http://dx.doi.org/10.1175/1520-0469(1989)046<3328:GPOTQB>2.0.CO;2

[18] Shiotini, M. (1992) Annual Quasi-Biennial and El-Nino-Southern Oscillation (ENSO) Time Scale Variation in Equatorial Total Ozone. Journal of Geophysical Research, 97, 7625-7633. http://dx.doi.org/10.1029/92JD00530

[19] Thompson, A.M. and Hudson, R.D. (2000) Tropical Tropospheric Ozone (TTO) Maps from Nimbus7 and Earth Probe TOMS by the Modified Residual Method: Evaluation with Sondes, ENSO Signal and Trends from Atlantic Regional Time Series. Journal of Geophysical Research, 105, 26961-26975.

[20] Hood, L. (1997) The Solar Cycle Variation of Total Ozone: Dynamical Forcing on the Lower Stratosphere. Journal of Geophysical Research, 102, 1355-1370. http://dx.doi.org/10.1029/96JD00210

[21] Martin, R.V., Jacob, D.J., Logan, J.A., Ziemko, J.R. and Washington, R. (2000) Detection of Lightening Influence on 
Tropical Tropospheric Ozone. Geophysical Research Letterers, 27, 1639-1642. http://dx.doi.org/10.1029/1999GL011181

[22] Ziemke, J.R. and Chandra, S. (1999) Seasonal and Interannual Variabilities in Tropical Tropospheric Ozone. Journal of Geophysical Research, 104, 21425-21442. http://dx.doi.org/10.1029/1999JD900277

[23] Mani, A. and Sreedharan, C.R. (1973) Studies of Variations in the Vertical Ozone Profiles over India. Pure and Applied Geophysics, 108, 1180-1191. http://dx.doi.org/10.1007/BF00881070

[24] Tiwari, V.S. (1992) Ozone Variations over Tropics: Trends Reveled from Dobson Measurements over Indian Stations. Mausam, 43, 65-70.

[25] Kundu, N. and Jain, M. (1993) Total Ozone Trends over Low Latitude Indian Stations. Geophysical Research Letters, 20, 2881-2883. http://dx.doi.org/10.1029/93GL03306

[26] Chakrabarty, D.K., Peshin, S.K., Pandya, K.V. and Shah, N.C. (1998) Long-Term Trend of Ozone Column over the Indian Region. Journal of Geophysical Research, 103, 19245-19251.

[27] Jadin, E.A. (1998) Interannual Variability of Total Ozone and Stratospheric Angular Momentum. International Journal of Geomagnetism and Aeronomy, 1. http://elpub.wdcb.ru/journals/ijga/v01/gai97142/gai97142.htm

[28] Chandra, S., Ziemke, J.R., Bhartia, P.K. and Martin, R.V. (2002) Tropical Tropospheric Ozone: Implications for Dynamics and Biomass Burning. Journal of Geophysical Research, 107, ACH 3-1-ACH 3-17. http://dx.doi.org/10.1029/2001JD000447

[29] McPeters, R.D. and Labour, G.C. (1996) An Assessment of Accuracy of 14.5 Years of Nimbus 7 TOMS Version \& Ozone Data by Comparison with the Dobson Network. Geophysical Research Letters, 23, 3695-3698. http://dx.doi.org/10.1029/96GL03539

[30] Kalnay, E., Kanamitsu, M., Kistler, R., Collins, W., Deaven, D., et al. (1996) The NCEP/NCAR 40-Year Reanalysis Project. Bulletin of American Meteorological Society, 77, 437-471. http://dx.doi.org/10.1175/1520-0477(1996)077<0437:TNYRP>2.0.CO;2

[31] Carter, M.M. and Elsner, J.B. (1996) Convective Rainfall Regions of Puerto Rico. International Journal of Climatology, 16, 1033-1043. http://dx.doi.org/10.1002/(SICI)1097-0088(199609)16:9<1033::AID-JOC77>3.0.CO;2-H

[32] Kaplunovsky, A.S. (2005) Factor Analysis in Environmental Studies. HAIT Journal of Science and Engineering B, 2, 54-94.

[33] Simon, A. and Mohankumar, K. (2004) Spatial Variability and Rainfall Characteristics of Kerala. Proceedings of the Indian Academy of Science (Earth Planetary Sciences), 113, 211-221. http://www.ias.ac.in/jess/june2004/Esb1559.pdf

[34] Morlet, J.S. (1983) Sampling Theory and Wave Propagation. In: Chen, C.H., Ed., Issue in Acoustics Signals-Image Processing and Recognition, NATO ASI Series, Vol. 1, Springer-Verlag, Beilin, 233-261.

[35] Brewer, A.M. (1949) Evidence for a World Circulation Provided by the Measurements of Helium and Water Vapor Distribution in the Stratosphere. Quarterly Journal of Royal Meteorological Society, 75, 351-363. http://dx.doi.org/10.1002/qj.49707532603

[36] Dobson, G.M.B. (1956) Origin and Distribution of the Polyatomic Molecules in the Atmosphere. Proceedings of the Royal Society A, 236, 187-193. http://dx.doi.org/10.1098/rspa.1956.0127

[37] Reed, R.J., Campbell, W.J., Rasmusson, L.A. and Rogers, D.G. (1961) Evidence of the Downward-Propagating Annual Wind Reversal in the Equatorial Stratosphere. Journal of Geophysical Research, 66, 813-818. http://dx.doi.org/10.1029/JZ066i003p00813

[38] Baldwin, M.P., Gray, L.J., Dunkerton, T.J., Hamilton, K., et al. (2001) The Quasi-Biennial Oscillation. Review of Geophysics, 39, 179-230. http://dx.doi.org/10.1029/1999RG000073

[39] Angel, J.K. (1993) Reexamination of the Relation between Depth of the Antarctic Ozone Hole, and an Equatorial QBO, and SST, 1962-1992. Geophysical Research Letters, 20, 1559-1562. http://dx.doi.org/10.1029/93GL01762

[40] Stolarski, R.S., Bloomfield, P., Mc Peters, R.D. and Herman, J.R. (1991) Total Ozone Trends Deduced from Nimbus 7 TOMS Data. Geophysical Research Letters, 18, 1015-1018. http://dx.doi.org/10.1029/91GL01302

[41] Hess, P.G. and O’Sullivan, D. (1995) A Three-Dimensional Modeling Study of the Extratropical Quasi-Bienniel Oscillation in Ozone. Journal of Atmospheric Science, 52, 1539-1554. http://dx.doi.org/10.1175/1520-0469(1995)052<1539:ATDMSO>2.0.CO;2

[42] Ramanathan, K.R. (1963) Bi-Annual Variation of Atmospheric Ozone over the Tropics. Quarterly Journal of Royal Meteorological Society, 89, 540-542. http://dx.doi.org/10.1002/qi.49708938209

[43] Angel, J.K. and Korshover, J. (1973) Qausi-Biennial and Long-Term Fluctuations in Total Ozone. Monthly Weather Review, 101, 426-443. http://dx.doi.org/10.1175/1520-0493(1973)101<0426:QALFIT>2.3.CO;2

[44] Gray, L.J. and Dunkerton, T.J. (1990) The Role of the Seasonal Cycle in the Quasi-Biennial Oscillation of Ozone. Journal of Atmospheric Science, 47, 2429-2451. 
http://dx.doi.org/10.1175/1520-0469(1990)047<2429:TROTSC>2.0.CO;2

[45] Garcia, R. and Solomon, S. (1987) A Possible Relationship between Interannual Variability in Antatctic Ozone and Quasi-Biennial Oscillation. Geophysical Research Letters, 14, 848-851. http://dx.doi.org/10.1029/GL014i008p00848 
Scientific Research Publishing (SCIRP) is one of the largest Open Access journal publishers. It is currently publishing more than 200 open access, online, peer-reviewed journals covering a wide range of academic disciplines. SCIRP serves the worldwide academic communities and contributes to the progress and application of science with its publication.

Other selected journals from SCIRP are listed as below. Submit your manuscript to us via either submit@scirp.org or Online Submission Portal.
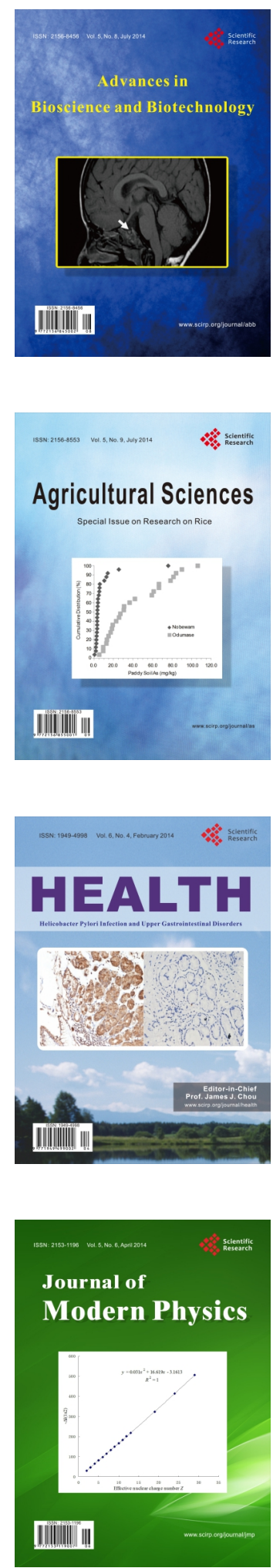
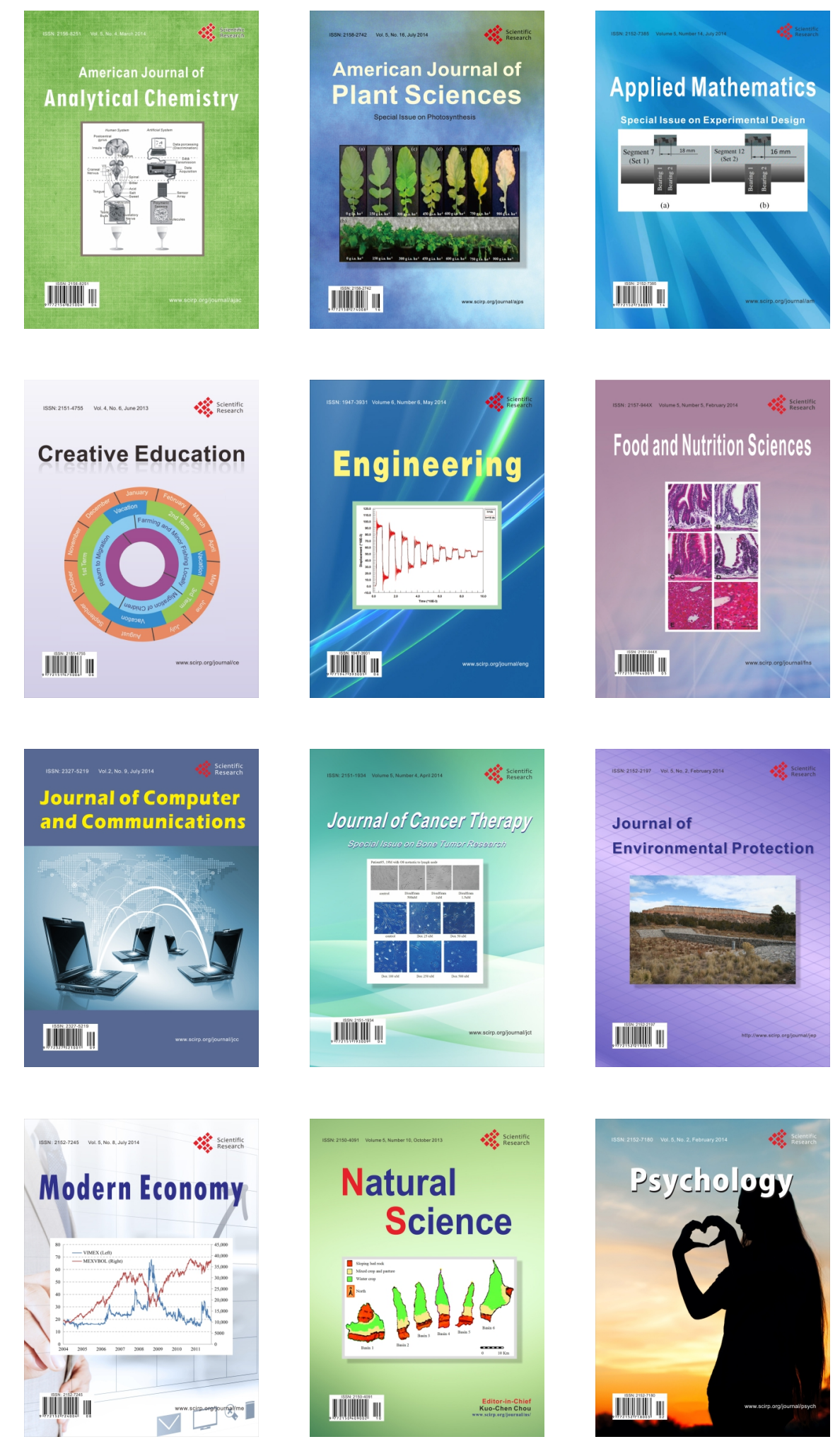